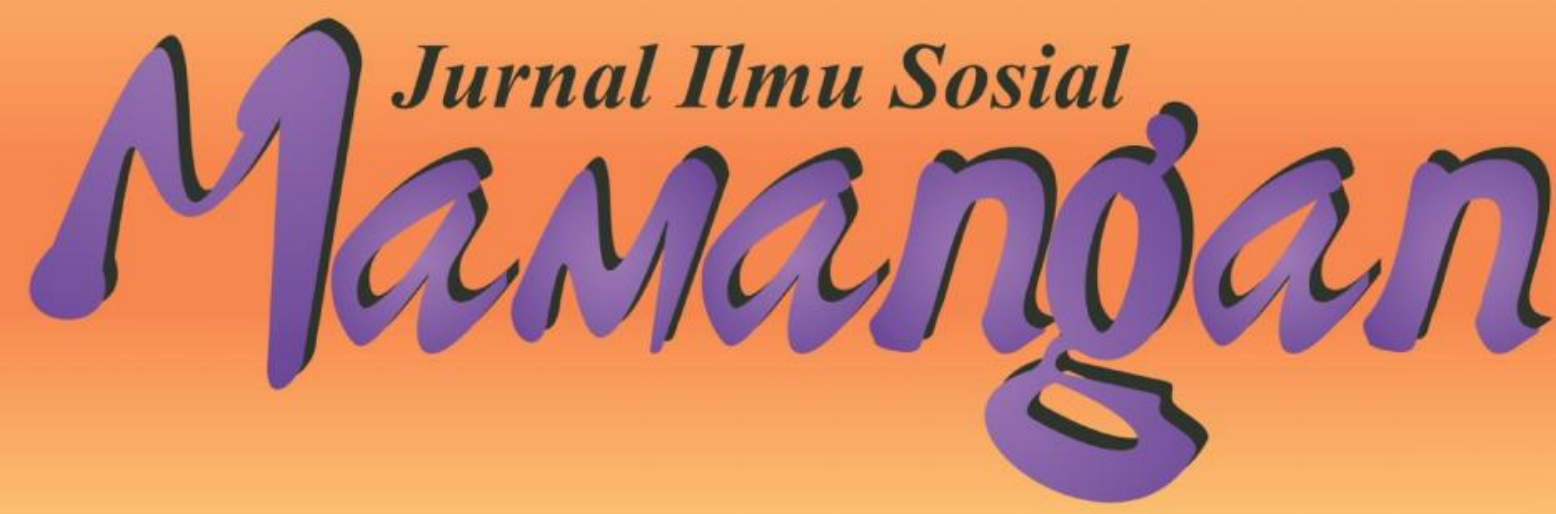

Kehidupan Sosial Ekonomi Petani Nilam Di Desa Taikako, Kec. Sikakap, Kab. Kepulauan Mentawai

Yanti Murni, Ansofino \& Meldawati

Dampak Sosial Konflik Kinali 1999-2010

Welly Ibrahim, Ansofino \& Ahmad Nurul Huda

Pasang Surut Sosial Ekonomi Petani Cengkeh Di Nagari Koto Anau, Kec. Lembang Jaya, Kab. Solok 1960-2011

Yosefrizal, Sabar \& Witrianto

Perubahan Sosial Ekonomi Masyarakat Pasca Pengembangan Wisata Bahari Di Kepulauan Sikakap, Kabupaten Mentawai

Ismi Andriyani, Etmi Hardi \& Liza Husnita

Persepsi Masyarakat Petani Kelapa Terhadap Pendidikan Tinggi Anak Di Kecamatan Siberut Barat, Kabupaten Kepulauan Mentawai

A. Tisnawati Tapondhadhai, Ansofino \& Ranti Nazmi

Kecendrungan Masyarakat Membeli Lahan Sengketa Di Kecamatan VII Koto, Kabupaten Tebo, Jambi

Esri Eni Dewi Mukti, Slamet Rianto \& Dasrizal 


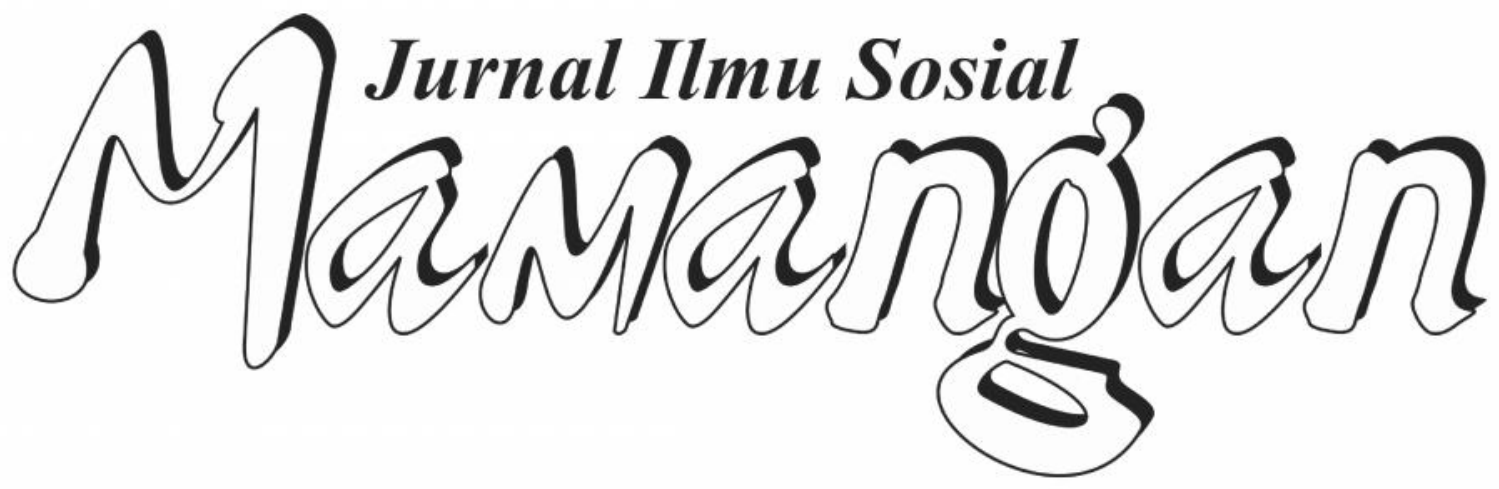




\section{Mitra Bestari}

Prof. Dr. Afrizal, MA. (FISIP, Unand Padang)

Dr. A. Latief Wiyata, M. Si. (Universitas Jember, Jember)

Prof. Dr. Badaruddin, M. Si. (FISIP, USU Medan)

Dr. Fikarwin Zuska, M. Si. (FISIP, USU Medan)

Nurus Shalihin, M. Si., Ph.D. (Fak. Ushuluddin IAIN Imam Bonjol Padang)

Dr. Semiarto A. Purwanto, M. Si. (FISIP, UI Jakarta)

Dr. Wahyu Wibowo, M. Si. (Universitas Nasional, Jakarta)

\section{Dewan Redaksi}

Dr. Zusmelia, M. Si.

Dr. Maihasni, M. Si.

Adiyalmon, S. Ag., M. Pd.

Firdaus, S. Sos., M. Si.

\section{Pemimpin Redaksi}

Firdaus, S. Sos., M. Si.

\section{Anggota Redaksi}

Dian Kurnia Anggreta, S. Sos., M. Si.

Rinel Fitlayeni, S. Sos., MA.

Surya Prahara, SH.

ISSN: 2301-8496

\section{Alamat Redaksi:}

Laboratorium Program Studi Pendidikan Sosiologi, STKIP PGRI Padang

Jl. Gunung Pangilun, Padang

Email: redaksimamangan@yahoo.com

Penerbit :

Program Studi Pendidikan Sosiologi, STKIP PGRI Padang

\section{Contac person :}

Firdaus (Hp. 085263881221/Email : daus gila@yahoo.com) 


\section{DAFTAR ISI}

Kehidupan Sosial Ekonomi Petani Nilam Di Desa Taikako, Kec. Sikakap, Kab. Kepulauan Mentawai

Yanti Murni, Ansofino \& Meldawati.

$60-72$

Dampak Sosial Konflik Kinali 1999-2010

Welly Ibrahim, Ansofino \& Ahmad Nurul Huda

Pasang Surut Sosial Ekonomi Petani Cengkeh Di Nagari Koto Anau, kec. Lembang Jaya, Kab. Solok 1960-2011

Yosefrizal, Sabar, Witrianto

Perubahan Sosial Ekonomi Masyarakat Pasca Pengembangan Wisata Bahari Di Kepulauan Sikakap, Kabupaten Mentawai

Persepsi Masyarakat Petani Kelapa Terhadap Pendidikan Tinggi Anak Di Kecamatan Siberut Barat, Kabupaten Kepulauan Mentawai

A. Tisnawati Tapondhadhai, Ansofino \& Ranti Nazmi.

Kecendrungan Masyarakat Membeli Lahan Sengketa Di Kecamatan VII Koto, Kabupaten Tebo, Jambi 


\title{
KECENDRUNGAN MASYARAKAT MEMBELI LAHAN SENGKETA DI KECAMATAN VII KOTO KABUPATEN TEBO JAMBI
}

\author{
Esri Eni Dewi Mukti, Slamet Rianto \& Dasrizal \\ Sekolah Tinggi Keguruan dan Ilmu Pendidikan (STKIP) PGRI Sumatera Barat
}

\begin{abstract}
This article discusses factors that affect the public interest to buy land disputes in District VII Koto Tebo regency in Jambi, The study population across the head of the family who purchased the disputed land in District VII Koto Tebo regency in Jambi totaling 432 KK, Samples were taken in two ways, samples were taken in a region purposive sampling. Sample of respondents with proportional random sampling technique samples was determined that a large proportion of $25 \%$ so that the amount of sample is $100 \mathrm{KK}$. Based on the correlation analysis it can be concluded as follows: (1) there is a significant and positive impact on the public interest in a cheap price to buy the disputed land in District VII Koto Tebo Regency Jambi because $t_{\text {hitung }}>t_{\text {tabel, }}(2,651>1,660)$, low relationship strength $(r=0,259)$ and contributions made small $(6,7 \%),(2)$ there is a significant and positive influence physiographic against the public interest to buy land disputes in District VII Koto Tebo regency in Jambi because $t_{\text {hitung }}>t_{\text {tabel } ;}(5,217>1,660)$, the strength of the relationship was $(r=0,466)$ and contributions made by being $(21,7 \%)$, (3) there is a significant and positive effect transactions quickly against the public interest to buy land disputes in District VII Koto Tebo regency in Jambi, because $t_{\text {hitung }}>t_{\text {tabel; }}(3,724>1,660)$, low strength $(r=0,352)$ and contributions made small $(12,4 \%)$ and (4) There is a significant and positive effect of low prices, physiographic conditions and fast transactions to the public interest to buy land disputes in District VII Koto Tebo regency in Jambi $F_{\text {hitung }}>F_{\text {tabel }}(14,156>2,72)$, the strength of the relationship between these three variables to variable Y including being $(r=0,554)$ and contributions made, including being $30,7 \%)$.
\end{abstract}

\section{Keywords : Tanah Ulayat, Conflict Land, Purchasing Land,}

\begin{abstract}
ABSTRAK
Artikel ini membahas faktor-faktor yang mempengaruhi minat masyarakat membeli lahan sengketa di Kecamatan VII Koto Kabupaten Tebo Jambi. Populasi penelitian seluruh kepala keluarga yang membeli lahan sengketa di Kecamatan VII Kabupaten Koto Tebo Jambi yang berjumlah 432 KK. Sampel penelitian diambil dengan dua cara, sampel wilayah diambil seara purposive sampling. Sampel responden dengan teknik proporsional random sampling besarnya proporsi sampel ditentukan 25\% sehingga jumlah sampel penelitian adalah $100 \mathrm{KK}$. Berdasarakan analisis korelasi maka dapat diambil kesimpulan sebagai berikut: (1) terdapat pengaruh yang signifikan dan positif harga murah terhadap minat masyarakat membeli lahan sengketa di Kecamatan VII Kabupaten Koto Tebo jambi karena $t_{\text {hitung }}>t$ tabel; $(2,651>1,660)$, kekuatan hubungan rendah $(r=0,259)$ dan kontribusi yang diberikan kecil $(6,7 \%),(2)$ terdapat pengaruh yang signifikan dan positif fisiografi terhadap minat masyarakat membeli lahan sengketa di Kecamatan VII Kabupaten Koto Tebo Jambi karena $t_{\text {hitung }}>t$ tabel $;(5,217>1,660)$, kekuatan hubungan sedang $(r=0,466)$ dan kontribusi yang diberikan sebesar sedang $(21,7 \%)$, (3) terdapat pengaruh yang signifikan dan positif transaksi cepat terhadap minat masyarakat membeli lahan sengketa di Kecamatan VII Kabupaten Koto Tebo Jambi, karena $t_{\text {hitung }}>\mathrm{t}$ tabel;
\end{abstract}


$(3,724>1,660)$, kekuatan rendah $(r=0,352)$ dan kontribusi yang diberikan kecil $(12,4 \%)$ dan (4) Terdapat pengaruh yang signifikan dan positif harga murah, kondisi fisografis dan transaksi cepat terhadap minat masyarakat membeli lahan sengketa di Kecamatan VII Kabupaten Koto Tebo Jambi $\mathrm{F}_{\text {hitung }}>\mathrm{F}$ tabel $(14,156>2,72)$, kekuatan hubungan antara ketiga variabel tersebut terhadap variable $\mathrm{Y}$ termasuk sedang $(\mathrm{r}=0,554)$ dan kontribusi yang diberikan termasuk sedang $(30,7 \%)$.

\section{Kata Kunci: Tanah ulayat, Konflik Tanah, Pembelian Lahan}

\section{PENDAHULUAN}

Negara Republik Indonesia, yang susunan kehidupan rakyatnya, termasuk perekonomiannya, terutama masih bercorak agraria, bumi air dan ruang angkasa, sebagai Karunia Tuhan yang Maha Esa mempunyai fungsi yang amat penting untuk membangun masyarakat yang adi dan makmur sebagaimana yang dicita-citakan. Usaha untuk mencapai cita-cita Negara tersebut d atas, maka dibidang agraria perlu adanya suatu rencana (planning) mengenai peruntukan, penggunaan dan persediaan bumu, air dan ruang angkasa untuk berbagai kepentingan hidup rakyat dan Negara. Rencana umum (National Planning) yang meliputi seluruh wilayah Indonesia, yang kemudian diperinci menjadi rencana-rencana khusus (Regional Planning) dari tiap-tiap daerah. Denganadanya planning itu maka penggunaan tanah dapat dilakukan secara terpimpim dan teratur sehingga dapat membawa manfaat yang sebesar-besarnya bagi Negara dan Rakyat.

Berdasarkan penjelasan diiatas jelaslah bahwa tanah sebagai sumber utama bagi kehidupan manusia, yang telah dikaruniakan oleh Tuhan yang Maha Esa sebagai tumpuan masa depan kesejahteraan manusia itu sendiri. Berdasarakan jalan pemikiran tersebut agar tanah digunakan sebesar-besar kemakmuran dan kesejahteraan rakyat. Undang-undang Nomor 5 tahun 1960, tentang peratuan Dasar pokokpokok Agraria yang biasa disebut UndangUndang Pokok Agraria (UUPA). Mengisyaratkan bahwa tanah itu pada tingkatan tertinggi dikuasai oleh Negara sebagai organisasi sekuruh rakyat. Secara konstitusional, UUD 1945 dalam pasal 33 ayat (3) menyatakan bahwa "bumi , air, ruang angkasa serta kekayaan alam yang terkandung didalamnya dikuasai oleh Negara dan dipergunakan untuk sebesar-besar kemakmuran rakyat".

Tanah merupakan kebutuhan hidup manusia yang sangat mendasar. Manusia hidup serta melakukan aktivitas di atas tanah sehinggga setiap saat manusia selalu berhubungan dengan tanah dapat dikatakan hampir semua kegiatan hidup manusia baik secara langsung maupun tidak langsung selalu memerlukan tanah, bahkan sampai pada saat manusiia meninggal dunia masih memerlukan tanah untuk penguburannya begitu pentingnya tanah bagi kehidupan manusia, maka setiap orang akan selalu berusaha memiliki dan menguasainya. Dengan halnya hal tersebut maka dapat menimbulkan suatu sengketa tanah di dalam masyarakat.

Setelah manusia berhasil memiliki tanah yang menjadi keinginan selanjutnya adalah dapat menguasai tanah tersebut sepenuhnya yang di perkuat oleh bukti hukum yang sah seperti adanya sertifikat atas tanah agar tidak ada pihak yang merasa dirugikan atau keberatan yang suatu waktu dapat mengganggu gugat atas kepemilikan tabag tersebut. Tetapi karena keinginan atau minat masyarakat yang begitu besar untuk memiliki dan menguasai tanah, di Kecamata VII Koto masyarakat justru membeli lahan atau tanah yang tidak memiliki sertifikat karena tanah yang di perjual belikan ini merupakan tanah sengketa antara masyarakat dengan PT. Tebo Multi Agro sejak tahun 2000.

(Sumardjono 2008) mengemukakan pitologi kasus-kasus di bidang partanahan secara garis besar dapat besar dapat dipilah menjadi llima kelompok yakni: 1 . Kasus-kasus yang berkenaan dengan garapan rakyat atas tanah-tanah perkebunan, kehutanan dan lainlain seperti yang terjadi di Kecamatan VII Koto Kab.Tebo Jambi, 2. Kasus-kasus berkenaan dengan pelanggaran peraturan 
landreform seperti yang pernah terjadi mengkalih bali yang yang berawal dari tanah adat kemudian ada peraturan landreform kemudian kepemilikan atas tanah dibatasi, 3. Kasus-kasus yang berkenaan dengan aksesakses penyediaan tanah untuk pembangunan sengketa perdata yang berkenaan dengan masalah tanah seperti yang pernah terjadi di makasar untuk penetapan hak, 4. Sengketa berkenaan dengan tanah ulayat seperti yang terjadi di muaro pinggai dengan desa saniang bakar kab. Solok yang berawal dari pengelolaantanah adat di batasi kedua desa.

Kasus pertanahan pada hakekatnya merupakan benturan kepentingan (conflict of interest) di bidang pertanahan antara siap denagn siapa, sebagai contoh kongkret antara perorangan dengan perorangan, perorangan dengan badan hukum dengan badan hukum dan lain sebagainya. Sehubungan dengan hal tersebut di atas, guna kapastian hukum yang dimanfaatkan UUPA, maka terhadap kasus pertanahan dimaksud antara lain dapat diberikan respons / reaksi / penyelesaian kepada yaang berkepentingan (masyarakat dan pemerintah).

Berdasarkan temuan dilapangan menunjukkan bahwa di Kecamatan VII Koto kab.Tebo Jambi harga jual atas tanah lebih rendah jika dibandingkan dengan daerahdaerah lain, harga jual untuk tanah kosong diatas 10 juta / ha sedangkan untuk tanah yang sudah ada sawit berumur 1,5 tahun harga jual tanah nya bisa mencapai 25 juta/ha lebih tinggi dibandingkan di Kecamatan VII Koto Kab.Tebo Jambi yang hanya sekitar 7 sampai 8 juta/ha untuk tanah kosong dan 13 sampai 15 juat/ha untuk tanah yang sudah ada tanaman nya. Selain dari harga tanah yang relatif miring di Kecamatan VII Koto Kab.Tebo Jambi memilik kondisi fisiografis yang merupakan dataran mempermudah masyarakat dalam mengelola lahan tersebut menjadi suatu lahan pertanian maupun perkebunan. Selain itu di dukung oleh lahan yang awalnya adalah hutan asli yang dialih fungsikan sebagai lahan pertanian sehingga tingkat kesuburan tanahnya masih bagus dan cocok untuk dijadikan sebagai lahan pertanian maupun perkebunan. Transaksi jual beli tanah yang dilakukan di Kecamatan VII Koto Kab.Tebo Jambi tidak lah sulit karena tanpa sertifikat dan hanya menggunakan kwitansi pembayaran saja, selain itu di Kecamatan VII Koto Kab.Tebo Jambi ini juga terdapat banyaknya pendduduk yang didominasi oleh pendatangdari dalam maupun luar daerah jambi, dan banyak terdapat masyarakat berhasil dalam pengelolaan tanah tersebut mengalih fungsikan hutan menjadi area pertanian.

Kenyataan yang ditemukan dilapangan menunjukkan kebanyakan dari masyarakat yang memebeli lahan sengketa di Kecamatan VII Koto Kab.Tebo Jambi adalah masyarakat yang memiliki tingkat pendidikan yang beraneka ragam mulai dari yang tidak sekolah sampai yang berpendidikan tinggi. Penulis menduga bahwa banyak yang mempengaruhi minat masyarakat untuk membeli lahan sengketa di Kecamatan VII Koto Kab.Tebo Jambi dikarenakan harga lahan yang murah, kondisi geografi, kesuburan tanah, transaksi yang cepat, tingkat pendidikan, dan motivasi lingkungan sekitar. Dari uraian diatas perumusan masalahnya adalah: (1) apakah harga murah mempengaruhi minat masyarakat membeli lahan sengketa di Kecamatan VII Koto Kabupaten Tebo, (2) apakah kondisi fisografi memepengaruhi minat masyarakat memblei lahan sengketa di Kecamatan VII Koto Kabupaten Tebo, (3) apakah transaksi cepat mempengaruhi minat masyarakat membeli lahan sengketa di Kecamatan VII Koto kabupaten tebo, dan (4) apakah harga murah, kondisi fisiografi dan transaksi cepat secara bersama-sama mempengaruhi minat masyarakat membeli lahan sengketa di Kecamatan VII Koto Kabupaten Tebo.

\section{TINJAUAN PUSTAKA}

Secara tertimologi minat adalah keinginan, kesukaan dan kemauan tehadap suatu hal. Minat merupakan kegemaran atau aspek kejiwaan dari diri seseorang yang tertuju pada suatu objek dan merupakan sambutan sadar setelah adanya ransangan dari objek tersebut. Minat dapat menjadi indikator kekuatan seseorang di area tertentu dimana ia akan termotivasi untuk mempelajarinya dan menunjukkan kinerjaa yang tinggi. Minat diawali dengan kesadaran seseorang menerima, baru akan timbul keinginan untuk bereaksi terhadap ransangan guna memaskan dirinya sendiri, sebagaimana yang telah dikemukakan oleh Slameto dalam (Djaali 2006) bahwa: minat adalah rasa lebih suka dan rasa ketertarikan pada suatu hal atau aktifitas tanpa ada yang menyuruh. 
Minat pada dasarnya adalah penerimaan akan suatu hubungan antara diri sendiri dengan sesuatu diluar diri, semakin kuat hubungan tersebut semakin besar minat.

\section{METODE PENELITIAN}

Penelitian ini menggunakan metode penelitian deskriptif korelasional. Penelitian dilaksansakan di Kecamatan VII Koto kabupaten Tebo Jambi. Untuk pengambilan sampel wilayah dalam penelitian ini dengan menggunakan teknik purposive sampling dan penentuan jumlah sampel dilakukan dengan tekhnik proporsial random sampling. Jenis data dalam penelitian ini menggunakan data primer dan sekunder, Pengumpulan data dalam penelitian ini wawancara dan observasi, dan juga sumber data dari data data primer diperoleh dari responden menggunakan angket, data sekunder di dapat dari pencatatan data-data.

\section{HASIL PENELITIAN}

\section{Pengaruh Harga Murah Terhadap Minat Beli Lahan Sengketa}

Pengujian hipotesisnya adalah sebagai berikut:

$\mathrm{H}_{0}=$ Tidak terdapat pengaruh yang signifikan dan positif harga murah terhadap minat masyarakat membeli lahan sengketa di Kecamatan VII Koto kabupaten Tebo jambi.

$\mathrm{H}_{1}=$ Terdapat pengaruh yang signifikan dan positif harga murah terhadap minat masyarakat membeli lahan sengketa dikecamatan VII Koto Tebo Jambi.

Hasil analisis pengaruh harga murah terhadap minat masyarakat membeli lahan sengketa di Kecamatan VII Koto Kabupaten tebo Jambi diperoleh seperti tabel berikut ini:

Tabel 1

Analisis Regresi Sedrehana antara Harga Murah dengan Variabel Minat

\begin{tabular}{|c|c|c|c|c|c|c|}
\hline \multirow[t]{2}{*}{$\begin{array}{l}\text { Vari } \\
\text { abel }\end{array}$} & \multirow[t]{2}{*}{$\begin{array}{c}\text { Koefisien } \\
\text { Regresi }\end{array}$} & \multirow[t]{2}{*}{$\begin{array}{c}\text { Standar } \\
\text { Error }\end{array}$} & \multicolumn{2}{|c|}{$\mathrm{t}$} & \multicolumn{2}{|c|}{$\begin{array}{c}\text { Pengujian } \\
\text { Hipotesis }\end{array}$} \\
\hline & & & Hitung & $\begin{array}{c}\text { Tabel a } \\
=0,05\end{array}$ & Ho & $\mathrm{H} 1$ \\
\hline $\mathrm{X}_{1}$ & 5,94 & 0,000 & 2,651 & 1,660 & & $\checkmark$ \\
\hline $\begin{array}{l}\text { Const } \\
\text { Stand } \\
\text { r. squ } \\
\text { r }\end{array}$ & $\begin{array}{l}\text { Error Of ea } \\
\text { e }\end{array}$ & $\begin{array}{r}=35,1 \\
=2,2 \\
=0,067 \\
=0,259\end{array}$ & & & & \\
\hline
\end{tabular}

Sumber : Pengolahan Data Primer, 2012

Berdasarkan analisis regresi linier sederhana dari data penelitian diperoleh koefisien regresi 5,94dan konstanta 35,149. Dengan demikian bentuk hubungan antara kedua variabel dapat disajikan dalam persamaan regresi $Y=35,149+5,94 X_{1}$. Hasil pengujian melalui uji $t$ diperoleh $t_{\text {hitung }}>t$ tabel sebesar 2,651, sedangkan variabel harga murah dengan minat masyarakat membeli lahan sengketa sebesar 0,259 yang berarti kekuatannya rendah. Besarnya kontribusi harga murah terhadap minat masyarakat membeli lahan sengketa sebesar 6,7\%. Dengan demikian terbukti bahwa koefisien tersebut berarti atau hipotesis yang diajukan diterima. Selanjutnya di uji menggunakan uji $\mathrm{F}$ hasilnya dapat dilihat pada tabel berikut ini:

Tabel 2

Analisis Varians Variabel Harga Murah dengan Minat masyarakat Membeli lahan sengketa.

\begin{tabular}{|l|c|c|c|c|c|c|}
\hline \multicolumn{1}{|c|}{ Source } & $\begin{array}{c}\text { Sum Of } \\
\text { Square }\end{array}$ & DF & Mean & Fo & \multicolumn{2}{c|}{ F Tabel } \\
\cline { 3 - 7 } & & & Square & & $\begin{array}{c}\mathrm{a}= \\
0,05\end{array}$ & $\begin{array}{c}\mathrm{a}= \\
0,01\end{array}$ \\
\hline $\begin{array}{l}\text { Regression } \\
\text { Residual }\end{array}$ & 125,007 & 1 & 100,293 & 6,141 & 3,94 & 6,90 \\
\hline Total & 1867,870 & 98 & 16,332 & & & \\
\hline
\end{tabular}

Sumber : Pengolahan Data Primer, 2012

Berdasarkan tabel di atas diperoleh harga F hitung sebesar 6,141 harga ini lebih besar dibandingkan dengan harga $\mathrm{F}$ tabel dengan DF pembilang 1 dan penyebut 98 pada taraf kepercayaan $a=0,01$ sebesar 6,90 , dengan membandingkan $\mathrm{F}_{\text {hitung }}$ dengan $\mathrm{F}$ tabel tersebut diketahui bahwa koefisien regresi signifikan $\mathrm{F}_{\text {hitung }}$ lebih besar dari $\mathrm{F}$ tabel untuk tingkat kepercayaan $a=0,05$.

\section{Tabel 3}

Analisis Keberartian Koefisien Korelasional rxy

\begin{tabular}{|c|c|c|}
\hline \multirow{2}{*}{ x $_{11} \mathrm{y}$} & \multicolumn{2}{|c|}{$\mathrm{r}$ tabel pada taraf signifikan } \\
\cline { 2 - 3 } & $\mathrm{a} 0,05$ & $\mathrm{a} 0,01$ \\
\hline 0,259 & 0,176 & 0,210 \\
\hline
\end{tabular}

Sumber : Pengolahan data Primer, 2012

Hasil perhitungan perhitungan koefisien korelasi variabel harga murah terhadap minat masyarakat membeli lahan sengketa rxy sebesar 0,259. Hasil pengujian harga murah berpengaruh terhadap minat masyarakat membeli lahan sengketa secara signifikan melalui model regresi $\mathrm{Y}=35,149+5,94 \mathrm{X}_{1}$. Untuk lebih jelasnya dapat dilihat pada grafik berikut ini: 
Gambar 1

Pengaruh Harga Murah Terhadap Minat Beli Lahan Sengketa

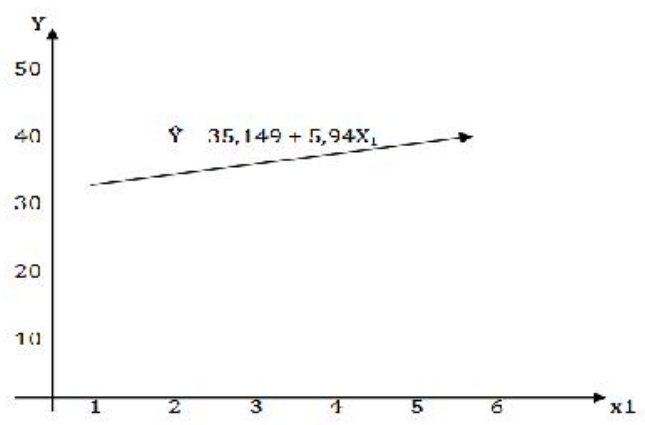

Keterangan : $\quad Y=$ Minat Masyarakat membeli lahan Sengket

Berdasarkan gambar diatas terdapat pengaruh harga murah terhadap minat masyarakat membeli lahan sengketa di Kecamatan VII Koto Kabupaten Tebo Jambi signifikan sekaligus menolak hipotesis kerja. Kesimpulannya adalah harga murah berpengaruh secara signifikan dan positif terhadap minat masyarakat membeli lahan sengketa di Kecamatan VII koto kabupaten Tebo Jambi. Harga murah memberi kontribusi sebesar 5,75 terhadap minat masyarakat membeli lahan sengketa.

\section{Pengaruh Kondisi Fisiografi Terhadap Minat Beli Lahan Sengketa}

Pengujian hipotesisnya adalah sebagai berikut:

$\mathrm{H}_{0}=$ Tidak terdapat pengaruh yang signifikan dan positif kondisi fisiografi terhadap minat masyarakat membeli lahan sengketa di Kecamatan VII Koto Kabupaten Tebo jambi.

$\mathrm{H}_{1}=$ Terdapat pengaruh yang signifikan dan positif kondisi fisiografi terhadap minat masyarakat membeli lahan sengketa di Kecamatan VII Koto Kabupaten Tebo Jambi.

Hasil analisis pengaruh kondisi fisiografi terhadap minat masyarakat membeli lahan sengketa di Kecamatan VII Koto Kabupaten Tebo Jambi seperti tabel berikut ini:
Tabel 4

Analisis Regresi Sederhana Antara variabel kondisi Fisiografi Terhadap Minat

Masyarakat membeli Lahan sengketa

\begin{tabular}{|c|c|c|c|c|c|c|}
\hline \multirow[t]{2}{*}{ Variabel } & \multirow[t]{2}{*}{$\begin{array}{c}\text { Koefisien } \\
\text { Regresi }\end{array}$} & \multirow[t]{2}{*}{$\begin{array}{l}\text { Standar } \\
\text { Error }\end{array}$} & \multicolumn{2}{|c|}{$\mathrm{T}$} & \multicolumn{2}{|c|}{$\begin{array}{l}\text { Pengujian } \\
\text { Hipotesis }\end{array}$} \\
\hline & & & Hitung & $\begin{array}{c}\text { Tabel } \\
\mathrm{a}=0,05\end{array}$ & Ho & H1 \\
\hline $\mathrm{X}_{1}$ & 2,827 & 0,542 & 5,217 & 1,660 & & \\
\hline \multicolumn{2}{|c|}{$\begin{array}{l}\text { Constanta } \\
\text { Standar Error Of east } \\
\text { r. square } \\
\text { r }\end{array}$} & $\begin{array}{l}=30,09 \\
=3,86 \\
=0,217 \\
=0,466\end{array}$ & & & & \\
\hline
\end{tabular}

Sumber : Pengolahan Data Primer, 2012

Berdasarkan analisis regresi linier sederhana dari data penelitian diperoleh koefisien regresi 2,827. Dengan demikian bentuk hubungan dapat disajikan dalam persamaan regresi $Y=30,097+2,827 X_{2}$, hasil pengujian melalui uji $\mathrm{t}$ diperoleh $\mathrm{t}$ hitung sebesar 5,217, sedangkan $t$ tabel pada taraf kepercayaan $a=0,05$ sebesar 1,660 , kekuatan hubungan antara variabel kondisi fisiografi terhadap minat masyarakat membeli lahan sengketa sebesar 0,466 yang berarti memiliki kekuatan sedang. Besarnya kontribusi kondisi fisiografi terhadap minat masyarakat membeli lahan sengketa adalah sebesar21,7\%. Dengan demikian terbukti bahwa kondisi fisiografi berpengaruh terhadap minat masyarakat membeli lahan sengketa atau hipotesis yang diajukan diterima. Selanjutnya di uji menggunakan uji $\mathrm{F}$ adapun hasilnya dapat dilihat pada tabel berikut ini:

Tabel 5

Analisis Varians variabel Kondisi Fisografi terhadap Minat masyarakat Membeli Lahan Sengketa

\begin{tabular}{|l|c|c|c|c|c|c|}
\hline \multicolumn{1}{|c|}{ Source } & $\begin{array}{c}\text { Sum Of } \\
\text { Square }\end{array}$ & DF & $\begin{array}{c}\text { Mean } \\
\text { Square }\end{array}$ & Fo & \multicolumn{2}{|c|}{ F Tabel } \\
\cline { 3 - 7 } & & $\begin{array}{c}\mathrm{a}= \\
0,05\end{array}$ & $\begin{array}{c}\mathrm{a}= \\
0,01\end{array}$ \\
\hline $\begin{array}{l}\text { Regression } \\
\text { Residual }\end{array}$ & $\begin{array}{c}406,170 \\
1462,580\end{array}$ & $\begin{array}{c}1 \\
98\end{array}$ & $\begin{array}{c}406,170 \\
14,924\end{array}$ & 27,215 & 3,94 & 6,90 \\
\hline Total & 1868,750 & 99 & & & & \\
\hline
\end{tabular}

Sumber : Pengolahan Data Primer, 2012

Berdasarkan tabel di atas diperoleh harga $\mathrm{F}$ hitung sebesar 27,215, harga ini lebih besar dibandingkan dengan harga $\mathrm{F}$ tabel dengan $\mathrm{Df}$ pembilang 1 dan penyebut 98 pada taraf kepercayaan $\mathrm{a}=0,05$ sebesar 3,94 dan $\mathrm{a}=$ 0,01 sebesar 6,90 dengan membandingkan $F$ hitung dengan $\mathrm{F}$ tabel tersebut diketahui bahwa 
koefisien regresi signifikan karena $\mathrm{F}_{\text {hitung }}$ lebih besar dari $\mathrm{F}_{\text {tabel. }}$

\section{Tabel 6}

Analisis Keberartian Koefisien Korelasional $r x y$

\begin{tabular}{|c|c|c|}
\hline \multirow{2}{*}{ rx $_{2 y}$} & \multicolumn{2}{|c|}{ r tabel pada taraf signifikan } \\
\cline { 2 - 3 } & $\mathrm{a} 0,05$ & $\mathrm{a} 0,01$ \\
\hline 0,466 & 0,176 & 0,210 \\
\hline
\end{tabular}

Sumber : Pengolahan data Primer, 2012

Hasil perhitungan koefisien korelasi antara variabel kondisi fisiografi terhadap minat masyarakat membeli lahan sengketa rxy sebesar 0,466. Hasil pengujian menunjukkan kondisi fisiografi berpengaruh terhadap minat masyarakat membeli lahan sengketa, melalui model regresi $\mathrm{Y}=30,097+2,827 \mathrm{X}_{2}$, untuk lebih jelasnya dapat dilihat pada grafik berikut ini:

Gambar 2
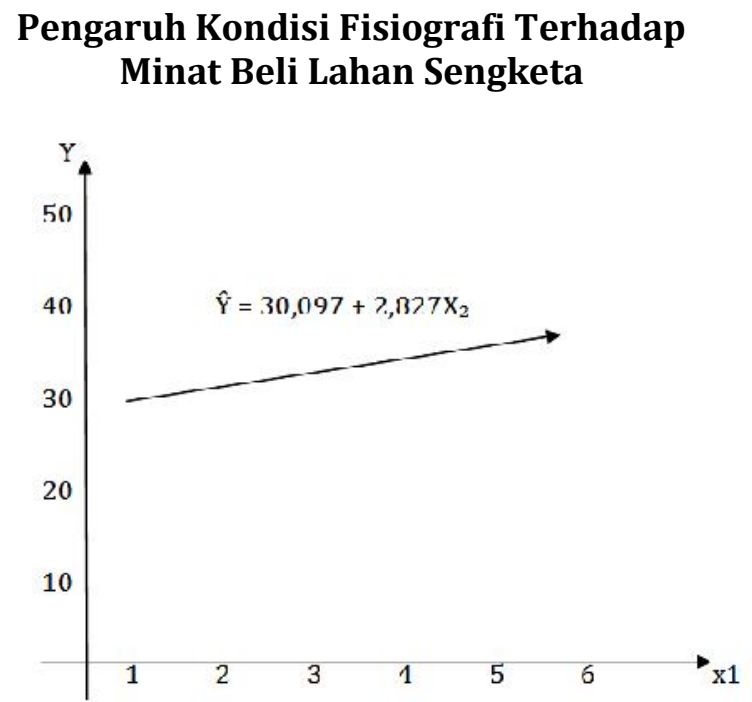

Keterangan : $\mathrm{Y}=$ Minat Masyarakat membeli lahan Sengketa $\mathrm{X}_{1}=$ Kondisi Fisiografi

Berdasarkan gambar diatas, pengaruh kondisi fisiografi terhadap minat masyarakat membeli lahan sengketa di Kecamatan VII Koto Kabupaten Tebo jambi signifikan sekaligus menolak hipotesis nol dan menerima hipotesis kerja. Kesimpulannya adalah kondisi fisiografi berpengaruhsecara signifikan dan positif terhadap minat masyarakat membeli lahan sengketa di Kecamatan VII Koto Kabupaten Tebo Jambi. Kondisi fisiografi memberi kontribusi sebesar $21,7 \%$ terhadap minat masyarakt membeli lahan sengketa.
Pengaruh Transaksi cepat Terhadap Minat Beli Lahan Sengketa

Pengujian hipotesisnya sebagai berikut:

$\mathrm{H}_{0}=$ tidak terdapat pengaruh yang signifikan dan positif transaksi cepat terhadap minat masyarakat membeli lahan sengketa di Kecamatan VII Koto Kabupaten Tebo Jambi.

$\mathrm{H}_{1}=$ terdapat pengaruh yang signifikan dan positif transaksi cepat terhadap minat masyarakat membeli lahan sengketa di Kecamatan VII Koto Kabupaten Tebo Jambi.

Hasil analisis pengaruh transaksi cepat terhadap minata masyarakat membeli lahan sengketa di Kecamatan VII Koto Kabupaten Tebo Jambi seperti tabel berikut ini :

Tabel 7

Analisis Regresi Sederhana Antara Variabel Transaksi Cepat Terhadap Minat Masyarakat Membeli Lahan Sengketa

\begin{tabular}{|l|c|c|c|c|c|c|}
\hline Variabel & $\begin{array}{c}\text { Koefisien } \\
\text { Regresi }\end{array}$ & $\begin{array}{c}\text { Standar } \\
\text { Error }\end{array}$ & \multicolumn{3}{|c|}{$\mathrm{T}$} & \multicolumn{2}{|c|}{$\begin{array}{c}\text { Pengujian } \\
\text { Hipotesis }\end{array}$} \\
\cline { 3 - 6 } & & Hitung & $\begin{array}{c}\text { Tabel } \\
\mathrm{a}= \\
0,05\end{array}$ & Ho & H1 \\
\hline $\mathrm{X}_{1}$ & 2,445 & 0,657 & 3,724 & 1,660 & & \\
\hline Constanta & $=33,015$ & & \\
Standar Error Of east & $=4,08$ \\
r. square & $=0,124$ \\
r & $=0,352$ \\
\hline
\end{tabular}

Sumber : pengolahan Data Primer, 2012

Berdasarakan analisis regresi linier sederhana dari data penelitian diperoleh koefisien regresi 2,445 dan konstanta 33,015. Dengan demikian persamaan regresi diperoleh sebagai berikut $\mathrm{Y}=33,015=$ $2,445 \mathrm{X}_{3}$, hasil pengujian melalui uji $\mathrm{t}$ diperoleh $t$ hitung sebesar 3,724, sedangkan $t$ tabel pada taraf kepercayaan $a=0,05$ sebesar 1,660, kekuatan hubungan antara variabel tingkat transaksi cepat terhadap minat masyarakat membeli lahan sengketa adalah $12,4 \%$. Dengan demikian terbukti bahwa transaksi cepat berpengarauh terhadap minat masyarakat membeli lahan sengketa atau hipotesis yang diajukan diterima. Selanjutnya di uji menggunakan uji $\mathrm{F}$ adapun hasilnya dapat dilihat pada tabel berkut ini: 
Tabel 8

Analisis Varians Variabel Transaksi Cepat Dengan Minat Masyarakat Membeli Lahan Sengketa

\begin{tabular}{|l|c|c|c|c|c|c|}
\hline Source & Sum Of & D & Mean & Fo & \multicolumn{2}{|c|}{ F Tabel } \\
\cline { 3 - 7 } & Square & F & Square & & $\begin{array}{c}\mathrm{a}= \\
0,0\end{array}$ & $\begin{array}{c}\mathrm{a}= \\
0,0 \\
\end{array}$ \\
& & & & & 5 & 1 \\
\hline Regressio & 231,679 & 1 & 231,67 & 13,86 & 3,9 & 6,9 \\
$\mathrm{n}$ & 1637,07 & 98 & 9 & 9 & 4 & 0 \\
Residual & 1 & & 16,705 & & & \\
\hline Total & $\begin{array}{c}1868,75 \\
0\end{array}$ & 99 & & & & \\
\hline
\end{tabular}

Sumber : Pengolahan Data Primer, 2012

Berdasarakan tabel di atas diperoleh harga F hitung sebesar 13,869, harga ini lebih besar dibandingkan dengan harga $\mathrm{F}$ tabel dengan $\mathrm{DF}$ pembilang 1 dan penyebut 98 pada taraf kepercayaan $a=0,05$ sebesar 3,96 dan $a=$ 0,01 sebesar 6,96 dengan membandingkan $F$ hitung dengan $\mathrm{F}$ tabel tersebut diketahui bahwa koefisien regresi signifikan karena $\mathrm{f}_{\text {hitung }}$ lebih besar dari $\mathrm{F}_{\text {tabel. }}$

Tabel 9: Analisis Keberartian Koefisian Korelasional rxy

\begin{tabular}{|c|c|c|}
\hline \multirow{2}{*}{$\mathrm{rx}_{2 \mathrm{y}} \mathrm{y}$} & \multicolumn{2}{|c|}{$\mathrm{r}$ tabel pada taraf signifikan } \\
\cline { 2 - 3 } & $\mathrm{a} 0,05$ & $\mathrm{a} 0,01$ \\
\hline 0,352 & 0,176 & 0,210 \\
\hline
\end{tabular}

Sumber : Pengolahan Data Primer, 2012

Hasil perhitungan koefisien korelasi variabel transaksi cepat terhadap minat masyarakat membeli lahan sengketa rxy sebesar 0,352. Hasil pengujian menunjukkan transaksi cepat berpengaruh terhadap minat masyarakat membeli lahan sengketa, melalui model regresi $\mathrm{Y}=33,015+2,445 \mathrm{X}_{3}$. Untuk lebih jelasnya dapat dilihat pada grafik berikut ini:

\section{Gambar 3}

Pengaruh Transaksi Cepat Terhadap Minat Beli Lahan Sengketa

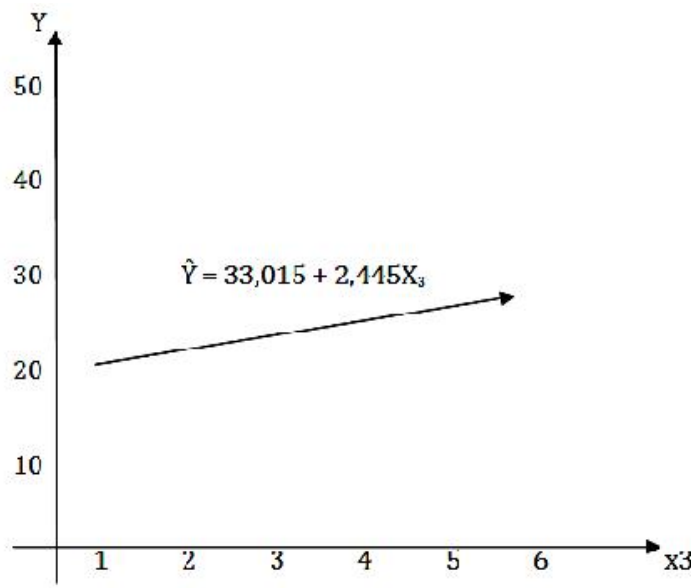

Berdasarkan gambar di atas, pengaruh transaksi cepat terhadap minat masyarakat membeli lahan sengketa di Kecamatan VII Koto Kabupaten Tebo jambi signifikan sekaligus menolak hipotesis nol dan menerima hipostesis kerja. Kesimpulannya adalah transaksi cepat berpengaruh secara signifikan dan positif terhadap minat masyarakat membeli lahan sengketa di Kecamatan VII Koto Kabupaten Tebo Jambi. Transaksi cepat memberi kontribusi sebesar $12,4 \%$ terhadap minat masyarakat membeli lahan sengketa di Kecamatan VII Koto Kabupaten Tebo Jambi.

\section{Pengaruh Harga Murah, Kondisi Fisiografi Dan Transaksi Cepat Secara Terhadap Minat Beli Lahan Sengketa}

Pengujian hipotesisnya adalah sebagai berikut:

$\mathrm{H}_{0}=$ tidak terdapat pengaruh yang signifikan dan positif harga murah, kondisi fisiografi dan transaksi cepat terhadap minat masyarakat memebli lahn sengketa di kecatan VII Koto Kabupaten Koto Kabupaten Tebo Jambi.

$\mathrm{H}_{1}=$ terdapat pengaruh yang signifikan dan positif harga murah, kondisi fisiografi dan transaksi cepa terhadap minat masyarakat membeli lahan sengketa di Kecamatan VII Koto kabupaten Tebo Jambi.

Hipotesis keempat dalam penelitian ini adalah harga murah, kondisi fisiografi dan transaksi cepat secara bersama-sama berpengaruh terhadap minat masyarakat membeli lahan sengketa di Kecamatan VII Koto kabupaten Tebo Jambi, untuk menguji hipotesis ketiga penelitian ini dilakukan melalui analisis regresi ganda (multiple regression) dan uji $\mathrm{F}$.

Dari analisis regresi linier berganda terhadap data penelitian, diperoleh hasil seperti terdapat pada tabel berikut:

Tabel 10 


\section{Analisis Regresi Ganda antara Variabel Harga Murah, Kondisi Fisiografi dan Transaksi Cepat Terhadap Minat Masyarakat Membeli Lahan Sengketa}

\begin{tabular}{|c|c|c|c|c|c|c|}
\hline \multirow[t]{2}{*}{ Variabel } & \multirow[t]{2}{*}{$\begin{array}{c}\text { Koefisien } \\
\text { Regresi }\end{array}$} & \multirow[t]{2}{*}{$\begin{array}{c}\text { Standar } \\
\text { Error }\end{array}$} & \multicolumn{2}{|c|}{$\mathrm{T}$} & \multicolumn{2}{|c|}{$\begin{array}{c}\text { Pengujian } \\
\text { Hipotesis }\end{array}$} \\
\hline & & & Hitung & $\begin{array}{c}\text { Tabel } \\
a= \\
0,05\end{array}$ & Ho & $\mathrm{H} 1$ \\
\hline $\mathrm{X}_{1}$ & 4,82 & 0,000 & 2,439 & 1,660 & & \\
\hline $\mathrm{X}_{2}$ & 2,175 & 0,550 & 3,951 & & & \\
\hline $\mathrm{X}_{3}$ & 1,667 & 0,624 & 2,689 & & & \\
\hline \multicolumn{7}{|c|}{ Constanta $=27,388$} \\
\hline \multicolumn{2}{|c|}{ Standar Error Of east } & \multicolumn{5}{|c|}{$=3,37$} \\
\hline \multicolumn{2}{|c|}{ Adjusted R squared } & \multicolumn{5}{|l|}{$=0,285$} \\
\hline \multicolumn{2}{|c|}{ r. squ } & \multicolumn{5}{|l|}{$=0,307$} \\
\hline \multicolumn{2}{|l|}{$\mathrm{r}$} & \multicolumn{5}{|l|}{$=0,554$} \\
\hline
\end{tabular}

Sumber : Pengolahan Data Primer, 2012

Dari analisis di atas untuk hubungan keempat variabel dapat disajikan suatu persamaan $\mathrm{Y}=27,388+4,82 \mathrm{X}_{1}+2,175 \mathrm{X}_{2}+$ $1,677 \mathrm{X}_{3}$.

Dari paparan di atas terlihat bahwa koefisien yang besar adalah kondisi fisiografi yaitu sebesar 4,82, artinya kondisi fisiografi merupakan variabel yang paling dominan terhadap minat masyarakat membeli lahan sengketa dibandingkan dengan variabel dengan harga murah dan transaksi cepat.

Persamaan regresi berganda di atas diperoleh harga determininasi ganda atau $\mathrm{R}$ Squared sebesar 0,307. Kontribusi yang diberikan variabel yang murah, kondisi fisiografi dan transaksi cepat terhadap minat masyarakat membeli lahan sengketa sebesar $30,7 \%$. Hal ini berati bahwa minat masyarakat membeli lahan sengketa (Y)ditentukan oleh variabel harga murah (X1), kondisi fisiografi (X2) dan transaksi cepat (X3) secara bersamasama.

Untuk mengetahui derajat keberartian regresi ganda tersebut selanjutnya di uji $\mathrm{F}$ hasilnya terlihat pada tabel dibawah ini :

Tabel 11

Daftar Analisis Variabel Harga Murah, Kondisi Fisiografi Dan Transaksi Cepat Terhadap Keberhasilan

\begin{tabular}{|l|c|c|c|c|c|c|}
\hline \multicolumn{1}{|c|}{ Source } & Sum Of & D & Mean & Fo & \multicolumn{2}{|c|}{ F Tabel } \\
\cline { 5 - 7 } & Square & F & Square & & $\begin{array}{c}\mathrm{a}= \\
0,0\end{array}$ & $\begin{array}{c}\mathrm{a}= \\
0,0\end{array}$ \\
& & & & & 5 & 1 \\
\hline Regressi & 572,97 & 1 & 190,99 & 14,15 & 2,7 & 4,0 \\
on & 0 & 9 & 0 & 0 & 2 & 4 \\
Residual & 1295,7 & 8 & 13,498 & & & \\
& 80 & & & & & \\
\hline Total & 1868,7 & 9 & & & & \\
& 50 & 9 & & & & \\
\hline
\end{tabular}

\section{Sumber : Pengolahan Data Primer, 2012}

Dari tabel di atas diperoleh harga $\mathrm{F}$ hitung sebesar 14,150. Harga ini lebih besar dibandingkan harga $\mathrm{f}$ tabel dengan DK pembilang 3 dan DK penyebut 96, pada taraf kepercayaan a $=0,05$ yaitu 2,72. Dengan membandingkan harga $\mathrm{F}$ hitung dengan $\mathrm{F}$ tabel tersebut diketahui bahwa koefisien regresi signifikan.

Tabel 12

Analisis Keberartian Koefisien Korelasi Berganda rxy

\begin{tabular}{|c|c|c|}
\hline \multirow{2}{*}{ r xy } & \multicolumn{2}{|c|}{ r tabel pada taraf signifikan } \\
\cline { 2 - 3 } & a 0,05 & a 0,01 \\
\hline 0,554 & 0,176 & 0,210 \\
\hline
\end{tabular}

Sumber : Pengolahan Data Primer, 2012

Catatan signifikan karena rxy yang diperoleh lebih besar $\mathrm{T}$ tabel pada $\mathrm{a}=0,05$ dan $a=0,01$.

Hasil analisis di atas dapat disimpulkan bahwa koefisien korelasi ganda (R) adalah 0,554 , ternyata berpengaruh signifikan dan sekaligus menerima hipotesis kerja yang menyatakan terdapat pengaruh yang positif dan signifikan antara harga murah, kondisi fisiografi dan transaksi cepat secara bersamasama terhadap minat masyarakat membeli lahan sengketa di Kecamatan VII Koto Tebo Jambi.

Kesimpulan yang ditarik dari pengujian di atas adalah (1) terdapat pengaruh yang positif dan signifikan antara harga murah, kondisi fisiografi dan transaksi cepat terhadap minat masyarakat membeli lahan sengketa di Kecamatan VII Koto Kabupaten tebo Jambi. (2) kekuatan hubungan ketiga variabel tersebut termasuk variabel $Y$ termasuk sedang $(r=0,554)$. (3) kontribusi yang diberikan ketiga variabel tersebut terhadap minat masyarakat membeli lahan sengketa adalah 30,7\%. (4) variabel harga murah, kondisi fisiografi dan transaksi cepat merupakan faktor yang mempengaruhi minat membeli lahan sengketa di Kecamatan VII Koto Kabupaten Tebo Jambi.

Pertama, untuk harga murah $\left(\mathrm{X}_{1}\right)$, harga umumnya tergolong tinggi $(40,0 \%)$. Hasil pengujian hipotesis menujkkan terdapat pengaruh yang signifikan dan positif harga murah terhadap minat masyarakat membeli lahan sengketa di Kecamatan VII Kotto Kabupaten Tebo Jambi karena $\mathrm{t}_{\text {hitung }}>\mathrm{t}_{\text {tabel; }}$; $(2,651>1,660)$, kekuatan hubungan harga 
murah terhadap minat masyarakat membeli lahan sengketa termasuk rendah $(r=0,259)$ dan kontribusi yang diberikan termasuk kecil $(6,7 \%)$.

Hal ini sesuai dengan pendapat (Simon 2007) harga adalah alat untuk memperoleh nilai dari pada pelanggan. Sedangkan menurut F. Kleinsteuber dan Siswanto Sutojo dalam Simon mendefenisikan harga sebagai sarana untuk mencapai target jumlah hasil penjualan dan keuntungan jangka pendek atau menengah. Sedangkan dalam konteks bisnis di sebutkan bahwa harga di artikan sebagai jumlah uang tertentu yang diserahkan pembeli pada penjual untuk memperoleh jumlah atau jasa tertentu.

Selanjutnya (Simamora 2001) harga adalah sejumlah nilai yang dipertukarkan untuk memperoleh suatu produk. Biasanya harga dihitung dengan nilai uang. Menetapkan harga sembarangan mudah yang sulit itu adalah menetapkan harga yang tepat yaitu tidak terlalu murah dan tidak terlalu mahal di mata konsumen masih memberikan keuntungan bagi perusahaan dan tidak menjadi kelemahan perusahaan dimata pesaing.

Kedua, untuk kondisi fisiografi $\left(\mathrm{X}_{2}\right)$, kondisi fisiografi umumnya dataran denagn persentase $50 \%$. Hasil penelitian ini menunjukkan terdapat pengaruh yang signifikan dan positif kondisi fisiografi terhadap minat masyarakat membeli lahan sengketa di Kecamatan VII Koto Kabupaten Tebo Jambi karena $\mathrm{t}$ hitung $>\mathrm{t}$ tabel; $(5,217>$ $1,660)$, kekuatan hubungan kondisi fisiografi terhadap minat masyarakat membeli lahan sengketa termasuk sedang $(r=0,466)$ dan kontribusi yang diberikan termasuk sedang $(21,7 \%)$.

Hal ini sesuai dengan pendapat Lrepp dalam (Rusna 2008) mengemukakan bahwa fisiografi adalah bentukan alam dipermukaan bumi yang dibedakan berdasarkan proses pembentukan dan evolusinya. Proses pembentukan dan evolusinya dapat berasal dari tenaga dalam bumi (endogen) dan dari luar bumi (eksogen). Tenaga dari dalam adalah tenaga yang disebabkan oleh penimbunan panas akibat adanya arus radio aktif dilapisan bumi paling dalam, tenaga ini dapat menimbulkan perubahan-perubahan (tinggi rendahnya) permukaan bumi sedangkan tenaga eksogen berasal dari luar bumi dan tenaga ini dapat menimbulkan perubahan pada permukaan bumi.

Ketiga, untuk transaksi cepat $\left(\mathrm{X}_{3}\right)$, proses transaksi yang terjadi sangat mudah $(47,0 \%)$ hasil penelitian ini menunjukkan transaksi cepat berpengaruh yang signifikan yang positif terhadap terhadap minat masyarakat membeli lahan sengketa di Kecamatan VII Koto Kabupaten Tebo Jambi, karena $\mathrm{t}_{\text {hitung }}>\mathrm{t}$ tabel; $(3,724>1,660)$, kekuatan hubungan transaksi cepat dengan minat masyarakat membeli lahan sengketa termasuk rendah $(\mathrm{r}=$ 0,352 ) dan kontribusi yang diberikan termasuk kecil $(12,4 \%)$.

Hal ini sesuai dengan pendapat (Bastian 2006) transaksi adalah tahap-tahap dalam proses bisnis organisasi baik yang bersifat fisik atau keuangan/finansial, transaksibisa bersifat interal atau eksternal, dengan kata lain , transaksi merupakan aktivitas-aktivitas yang direncanakan, diarahkan dan dikontrol oleh managemen.

Keempat, penelitian ini juga membuktikan bahwa terdapat pengaruh yang signifikan dan positif harga murah $\left(\mathrm{X}_{1}\right)$, kondisi fisiografi $\left(\mathrm{X}_{2}\right)$, dan transaksi cepat $\left(\mathrm{X}_{3}\right)$, terhadap minat masyarakat membeli lahan sengketa di Kecamatan VII Koto Kabupaten Tebo Jambi karena $F_{\text {hitung }}>F_{\text {tabel }}$ $(14,156>2,72)$, kekuatan hubungan antara ketiga variabel tersebut terhadap variabel $Y$ termasuk sedang $(r=0,554)$ dan kontribusi yang diberikan termasuk sedang $(30,7 \%)$. Kondisi fisiografi merupakan variabel yang paling dominan terhadap minat masyarakat membeli lahan sengketa dibandingkan dengan variabel harga murah dan trransaksi cepat karena t hitung kondisi fisiografi lebih besar dibandingkan t hitung harga murah dan transaksi cepat.

Hal ini sesuai dengan pendapat Crites 0 . John dalam (Djaali 2006) mengemukakan bahwa minat merupakan bagian dari ranah afeksi, mulai dari kesadaran sampai kepada pilihan nilai. Sedangkan Gerungan menyebutkan minat merupakan pengerahan perasaan dan menafsirkan untuk suatu hal (ada unsur seleksi). Dan Holland megemukakan bahwa minat adalah kecenderungan yaang tinggi terhadap sesuatu, minat tidak timbul sendirian, ada unsur kebutuhan.

Selain itu minat menurut Hilgar dalam (Susanti 2008) suatu proses yang tetap untuk memperhatikan dan memfokuskan diri pada 
sesuatu yang diminatinya dengan perasaan senang dan rasa puas. Menurut Aiken dalam (Susanti 2008) mengungkapkan defenisi minat sebagai suatu kesukaan terhadap kegiatan melebihi kegiatan lainnya.

\section{KESIMPULAN}

Berdasarkan temuan dan pembahasan hasil penelitian, maka kesimpulan hasil penelitian ini dapat dirumuskan sebagai berikut: (1) terdapat pengaruh yang signifikan dan positif harga murah terhadap minat masyarakat membeli lahan sengketa di Kecamatan VII Koto Kabupaten Tebo Jambi Karena $t_{\text {hitung }}>t_{\text {tabel }}(2,651>1,660)$, kekuatan hubungan hargaa murah terhadap minat masyarakat membeli lahan sengketa termasuk rendah $(r=0,259)$ dan kontribusi yang diberikan termasuk kecil $(6,7 \%)$, (2) terdapat pengaruh yang signifikan dan positif kondisi fisiografi terhadap minat masyarakat membeli lahan sengketa di Kecamatan VII Koto kabupaten Tebo Jambi karena $\mathrm{t}_{\text {hitung }}>\mathrm{t}$ tabel; $(5,217>1,660)$, kekuatan hubungan kondisi fisiografi terhadap minat masyarakat membeli lahan sengketa termasuk sedang $(\mathrm{r}$ $=0,466)$ dan kontribusi yang diberikan termasuk sedang $(21,7 \%)$, (3) terdapat pengaruh yang signifikan dan positif transaksi cepat terhadap minat masyarakat membeli lahan sengketa di Kecamatan VII Koto Kabupaten Tebo Jambi, karen $\mathrm{t}$ hitung; $\mathrm{t}$ tabel ; $(3,724>1,660)$, kekuatan hubungan transaksi cepat dengan minat masyarakat membeli lahansengketa termasuk rendah $(r=0,352)$ dan kontribusi yang diberikan termasuk kecil $(12,4 \%)$, dan (4) terdapat pengaruh yang signifikan dan positif harga murah, kondisi fisiografi dan transaksi cepat terhadap minat masyarakat membeli lahan sengketa di Kecamatan VII Koto Kabupaten Tebo Jambi karena $F$ hitung $>F$ tabel $(14,156>2,72)$, kekuatan hubungan antara ketiga variabel tersebut terhadap variabel $Y$ termasuk sedang ( $r=0,554)$ dan kontribusi yang diberikan termasuk sedang $(30,7 \%)$. Kondisi fisiografi merupakan variabel yang paling dominan terhadap minat masyarakat membeli lahan sengketa dibandingkan dengan variabel harga murah dan transaksi cepat karena t hitung kondisi fisiografi lebig besar dibandingkan $t$ hitung harga murah dan transaksi cepat.

\section{DAFTAR PUSTAKA}

Bastian, Indra. 2006. Akutansi Pendidikan. Jakarta: Erlangga.

Djaali. 2006. Psikologi Pendidikan. Jakarta: Erlangga.

Rusna, I. Wayan. 2008. "Karakteristik Zone Agroekosistemdan Kesesuaian Lahan Dilereng Selatan Gunung Batukaru Kabupaten Tabana." Universitas Udayana.

Simamora, Bilson. 2001. Memenangkan Pasar Dengan Pemasaran Efektif Dan Profitabel. Jakarta: Gramedia.

Simon, Herman dkk. 2007. Maximum Profit Minimum Problem. Bandung: Mizan Pustaka.

Sumardjono, Maria W. .. dkK. 2008. "Mediasi Sengketa Tanah." Kompas Media.

Susanti, Irva. 2008. "Hubungan Antara Minat Dan Motivasi Dengan Hasil Belajar Siswa Kelas XI Mata Pelajaran Geografi Di SMA Negeri 1 Lembang Jaya Kabupaten Solok." STKIP PGRI Sumbar. 
